Banco, Volume 1, Mei 2019

\title{
IMPLEMENTASI MARKETING MIX DALAM TABUNGAN BARATA iB BANK BTN SYARIAH KCPS PAREPARE
}

\author{
Anugrah Perdana \\ IAIN Parepare \\ anugrahperdana@yahoo.com \\ Abdul Hamid \\ IAIN Parepare \\ abdulhamid@iainpare.ac.id \\ Arqam \\ IAIN Parepare \\ arqam@iainpare.ac.id
}

\begin{abstract}
Syariah bank BTN KCPS parepare is a bank that supply batara savings ib which make them customers to save, this product is very attractive to the community .To quantity bank in indonesia has up and each bank had to be able to having the power of its own, both the public service, innovative products to stay in business and stable. This study aims to to know the implementation of marketing mix in batara ib on kcps parepare syariah bank btn . The research was conducted in syariah bank btn kcps parepare with a kind of qualitative research was conducted by adopting both fenomenology and in collect the primary data used method of interviews and observation. As for tekhnik analyzing of inductive around. This research result indicates that, the implementation of the program and the implementation of the marketing mix in syariah bank btn kcps parepare applied to all elements videlicet; product, price, place, promotion , people, physical evidence, processes
\end{abstract}

Keywords: Implementation, marketing mix, deposit

\section{Abstrak}

Bank BTN Syariah KCPS Parepare merupakan bank yang menyediakan produk tabungan Batara IB yang memudahkan nasabah untuk menabung, produk ini sangat diminati masyarakat. Dengan kuantitas bank di Indonesia semakin meningkat maka tiap bank harus bisa memiliki kekuatan tersendiri, baik dari segi pelayanan, produk yang inovatif untuk tetap bertahan dan stabil. Penelitian ini bertujuan untuk mengetahui implementasi marketing mix dalam Tabungan 
Batara IB pada Bank BTN Syariah KCPS Parepare. Penelitian ini dilakukan di Bank BTN Syariah KCPS Parepare dengan jenis metode penelitian kualitatif dengan menggunakan pendekatan fenomenology dan dalam mengumpulkan data primer digunakan metode wawancara dan observasi. Adapun tekhnik analisis datanya yaitu secara induktif. Hasil penelitian ini menunjukkan bahwa, Implementasi dalam program dan pelaksanaan marketing mix di Bank BTN Syariah KCPS Parepare diterapkan pada semua elemen yakni ; Product, Price,Place, Promotion, People, Physical Evidence, Process telah diterapkan dengan baik sesuai dengan teori marketing mix.

\section{Kata Kunci : Implementasi, Marketing Mix, Tabungan}

\section{A. Pendahuluan}

Perbankan dalam kehidupan suatu negara adalah salah satu agen pembangunan (agen of develovment). Hal ini dikarenakan adanya fungsi utama dari perbankan itu sendiri sebagai lembaga yang menghimpun dana dari masyarakat dalam bentuk simpanan dan menyalurkan kembali ke masyarakat dalam bentuk kredit atau pembiayaan. Fungsi inilah yang lazim disebut sebagai intermediasi keuangan (financial intermediay function). ${ }^{1}$

Bank Syariah atau bisa dikenal dengan bank Islam mempunyai sistem operasi dimana ia tidak mengandalkan pada bunga. Bank Islam atau biasa disebut dengan bank tanpa bunga ini, bisa dikatakan sebagai lembaga keuangan atau perbankan yang operasional dan produknya dikembangkan berlandaskan pada al-Qur'an dan Hadist Nabi SAW. Bank Islam adalah lembaga keuangan yang usaha pokoknya memberikan pembiayaan dan jasa-jasa lainnya dalam lalu lintas pembayaran tentang peredaran uang yang pengoperasiannya disesuaikan dengan prinsip syariat Islam. ${ }^{2}$

Bank syariah ada keharusan untuk memiliki Dewan Pengawas Syariah (DPS). DPS ini bertugas untuk mengawasi operasional bank dan produk-produknya agar sesuai dengan garis-garis syariah. Persaingan usaha antar bank syariah yang semakin tajam dewasa ini telah mendorong munculnya berbagai jenis produk dan sistem usaha dalam berbagai keunggulan kompetitif. Keadaan tersebut menuntut para pelaku perusahaan untuk lebih mempertahankan kelangsungan hidup perusahaan tersebut. Karena kondisi ini, telah menciptakan suatu sistem dan persaingan baru dalam dunia perbankan, bukan hanya persaingan bank syariah, tetapi juga antara bank syariah dan lembaga keuangan.

Sebuah fenomena nyata yang menuntut bank syariah untuk lebih antisipatif terhadap perubahan yang terjadi dalam dunia perbankan. Pihak perbankan harus memberi rangsangan dan kepercaayaan dengan balas jasa.

Pada saat ini, semakin banyak muncul lembaga keuangan bank dan lembaga keuangan non bank yang mengharuskan bank tersebut lebih giat lagi dalam mencari peluang-peluang yang lebih menguntungkan serta menciptkan produk baru yang sesuai dengan kebutuhan dan harapan nasabah guna meningkatkan jumlah nasabah. Dengan adanya perubahan selera nasabah, teknologi dan

\footnotetext{
${ }^{1}$ Trisadini P. Usanti dan Abd. Somad, Transaksi Bank Syariah, (Jakarta: PT Bumi Aksara, 2013), h. 1.

${ }^{2}$ http://www.banksyariah.net/2012/07/pengertian-bank-syariah 19.html.
} 
persaingan yang sangat pesat membuat Bank BTN Syariah harus mengembangkan secara terus menerus produk dan jasanya agar dapat eksis di dunia perbankan. Oleh karena itu, untuk mempertahankan dan meningkatkan perolehan tabungan, bank semakin kreatif dalam menciptakan produk dalam upaya memenuhi keinginan dan kebutuhan nasabah tabungannya. 
Konsumen selalu ingin mendapatkan produk dan jasa serta pemuas kebutuhan yang dapat memenuhi kebutuhan hidup mereka. Sebagian besar konsumen di Indonesia yang mempunyai dana lebih dan berperilaku sedemikian rupa, menjadi masyarakat konsumsi tinggi dalam memberi barang atau jasa bahkan ada konsumen yang khusus ke luar negeri untuk memuaskan kebutuhan dan keinginannya. Konsumen memiliki kedudukan sebagai salah satu kekuatan kompetitif melalui daya tawarnya. Daya tawar konsumen menjadi sangat penting karena merekalah yang mempunyai kebutuhan dan keinginan. Untuk memenuhi kebutuhan itu mereka jugalah yang mempunyai sarana pembelian (waktu dan uang), menentukan pilihan dan mengambil keputusan.

Perkembangan perbankan syariah di Indonesia merupakan suatu respon dari kelompok ekonom dan praktisi perbankan muslim yang berupaya mengakomodasi desakan dari berbagai pihak yang menginginkan agar tersedia jasa transaksi keuangan yang dilaksanakan sejalan dengan nilai moral dan prinsip-prinsip syariah Islam. Utamanya yang berkaitan dengan pelarangan praktek riba, kegiatan yang bersifat spekulatif yang serupa dengan perjudian, ketidakpastian dan pelanggaran prinsip keadilan dalam transaksi serta keharusan penyaluran dana investasi pada kegiatan usaha yang etis dan halal secara syariah. ${ }^{3}$

Namum maraknya perkembangan dan pertumbuhan bank syariah tersebut dipandang sinis oleh beberapa kalangan, bahkan kalangan umat Islam sendiri. Sinisme terhadap perbankan syariah tersebut dapat dilihat dari kepercayaan masyarakat Islam terhadap bank syariah sangat rendah. Berdasarkan dari hasil penelitian yang dilakukan oleh Bank Indonesia menunjukkan bahwa tidak sedikit di kalangan masyarakat yang masih kontra dengan perbankan syariah, salah satunya dengan keraguan terhadap konsistensi penerapan prinsip syariah.

Oleh karena itu, perbankan syariah harus mampu memaksimalkan strategisnya dalam usaha untuk mempertahankan dan meningkatkan nasabah bank syariah dengan mengukur kemampuan bank dalam memberikan produk, promosi yang dan layanan lebih baik pada nasabah dan sosialisasi kepada masyarakat sebagai cara untuk mengetahui penilaian serta kepuasan nasabah terhadap perkembangan bank.

Perusahaan yang baik sudah pasti memiliki manajemen yang baik dalam pengelolaannya. Manajemen diperlukan untuk mengkoordinasikan semua kegiatan yang ada dalam perusahaan agar menghasilkan suatu totalitas tindakan yang efektif dan efesien dalam rangka mencapai tujuan perusahaan. Untuk memahami dan mengerti dengan baik alat-alat manajemen yang dibutuhkan bagi kelangsungan hidup jangka panjang perusahaan, maka diperlukan penerapan strategi pemasaran yang tepat dan optimal.

Bank BTN Syariah memiliki produk unggulan yaitu Tabungan Batara IB merupakan salah satu produk dalam kelompok penghimpunan dana. Namun, dari observasi yang dilakukakan oleh peneliti bahwa masyarakat belum sepenuhnya memahami produk-produk yang ada di Bank BTN

\section{3.}

${ }^{3}$ Muhammad, Manajemen Bank Syari'ah, (Yogyakarta: Unit Penerbit dan Percetakan AMPYKPN, 2002), h. 
Syariah KCPS Parepare. Karena Bank BTN Syariah KCPS Parepare Hanya berfokus ke KPR (Kredit Kepemilikan Rumah. Dari observasi peneliti melihat kekurangan dari Bank BTN Syariah adalah bagian marketing atau pemasaran, Sehingga produk-produk lainnya kurang dipasarkan kepada masyarakat khususnya Tabungan Batara IB.

Berdasarkan latar belakang yang telah di uraikan sebelumnya, peneliti ingin mengetahui lebih jauh implementasi marketing mix terkhusus pada produk Tabungan Batara IB di Bank BTN Syariah KCPS Parepare, karena secara konsep elemen yang terkandung didalamnya sama, namun marketing mix didalam penerapannya tentu berbeda-beda. Peneliti ingin menelusuri lebih jauh, apakah seluruh elemen-elemen marketing mix digunakan dalam operasional perbankan atau tidak. Pentingnya penulis mengungkap masalah tersebut diharapkan mampu menjadi tolak ukur bagi lembaga perbankan dalam melakukan pemasarannya dan sebagai teori tambahan bagi pembaca maupun penulis sendiri.

\section{B. Diskusi dan Pembahasan}

\section{Gambaran Umum Lokasi Penelitian}

Visi dan Misi PT. Bank Tabungan Negara (Persero), Tbk. Kantor Cabang Pembantu Syariah Parepare sejalan dengan Visi Bank Tabungan Negara konvensional yang merupakan Strategic Business Unit dengan peran untuk meningkatkan pelayanan dan pangsa pasar sehingga Bank BTN tumbuh dan berkembang dimasa yang akan datang. Bank Tabungan Negara Syariah juga sebagai pelengkap dari bisnis perbankan dimana secara konvensional tidak dapat terlayani.

a. Visi PT. Bank Tabungan Negara (Persero), Tbk. Kantor Cabang Pembantu Syariah Parepare. "Menjadi Bank Syariah yang terdepan di Indonesia dalam pembiayaan perumahan dan industry ikutannya."

b. Misi PT. Bank Tabungan Negara (Persero), Tbk. Kantor Cabang Pembantu Syariah Parepare.

1) Menyediakan produk dan jasa yang inovatif serta layanan unggul yang fokus pada pembiayaan perumahan dan industri ikutannya.

2) Mengembangkan human capital yang berkualitas dan memiliki integritas tinggi serta penerapan Good Corporate Governance.

3) Meningkatkan keunggulan kompetitif melalui teknologi informasi terkini.

4) Memedulikan kepentingan masyarakat dan lingkungannya..1.4 Program yang Dilaksanakan

Program yang dilaksanakan pada Bank Tabungan Negara (Persero), Tbk. Kantor Cabang Pembantu Syariah Parepare yaitu program penghimpunan dana dan program pembiayaan.

a. Program penghimpunan dana yang dilaksanakan

1) Tabungan Batara iB 
Tabungan Batara iB merupakan produk simpanan dana yang berakad wadi'ah atau titipan, dimana bank dapat memberikan bonus yang menguntungkan dan bersaing bagi nasabah, selain dari itu nasabah juga dapat menerima bonus yang menarik yang sesuai dengan kebiajakan bank, imbalan juga dapat dipotong untuk zakat, infaq dan shadaqah. Berdasarkan benefit atau manfaat dari program ini yaitu, yang pertama mendapatkan bonus yang menarik (sesuai kebijakan bank). Kedua, Imbalan dapat dipotong untuk zakat, infaq dan shadaqah. Ketiga, penyetoran dan penarikan dapat dilakukan di seluruh outlet BTN Syariah yang menjadi Kantor Layanan Syariah di seluruh wilayah Indonesia.

2) Tabungan Prima iB

Tabungan Prima iB merupakan produk simpanan dana berakad mudharabah mutlaqah atau investasi, bank memberikan bagi hasil yang menguntungkan dan bersaing bagi nasabah, imbalan juga dapat dipotong untuk zakat, infaq dan shadaqah.

Berdasarkan benefit atau manfaat dari program ini yaitu, yang pertama mendapatkan bagi hasil yang kompetitif. Kedua, imbalan dapat dipotong untuk zakat, infaq dan shadaqah. Ketiga, penyetoran dan penarikan dapat dilakukan di seluruh outlet BTN Syariah yang menjadi Kantor Layanan Syariah di seluruh wilayah Indonesia.

3) Deposito BTN iB

Deposito BTN iB merupakan produk investasi berjangka berdasarkan prinsip mudharabah mutlaqah atau investasi, sistem bagi hasil yang diberikan secara kompetitif dan jangka waktu yang sangat fleksibel sesuai dengan kebutuhan.

4) KPR BTN Subsidi iB

Program KPR subsidi ini diberikan kepada nasabah perorangan yang tergolong masyarakat berpenghasilan rendah (MBR) dengan menggunakan akad murabahah atau jual beli dalam rangka pemilikan rumah atau rusun yang merupakan program pemerintah. Berdasarkan benefit atau manfaat dari program ini yaitu, yang pertama prosesnya, yang mudah dan cepat. Kedua, angsuran ringan dan tetap sampai dengan lunas. Ketiga, asuransi jiwa dan kebakaran yang diberikan secara gratis. .

5) KPR BTN Platinum iB

Program KPR platinum ini diberikan kepada nasabah perorangan dengan penggunaan akad murabahah atau jual beli dalam rangka pemilikan rumah, ruko, rukan, rusun atau apartemen kondisi baru maupun second.

Berdasarkan benefit atau manfaat dari program ini yaitu, yang pertama prosesnya, yang mudah dan cepat. Kedua, margin yang kompetitif. Ketiga, asuransi jiwa yang diberikan sesuai usia pemohon dan asuransi kebakaran yang diberikan sesuai dengan nilai operasional bangunan.

Berdasarkan fitur atau karakteristik dari program KPR BTN Platinum iB ini yaitu, jangka waktu yang diberikan sampai dengan 20 tahun dengan syarat tidak melebihi sisa jangka 
waktu hak atas tanah minus 1 tahun (untuk SHGB). Terdapat pilihan angsuran fixed atau berjenjang, dan harga acuan yang digunakan adalah harga jual setelah dikurangi diskon atau harga pasar wajar (mana yang lebih rendah).

6) Pembiayaan Multimanfaat BTN iB

Pembiayaan Multimanfaat BTN iB inidiberikan bagi para pegawai yang masih aktif dimana produk ini digunakan untuk keperluan pembelian berbagai jenis barangelektronik atau furniture, dengan menggunakan akad murabahah atau jual beli.

Berdasarkan benefit atau manfaat dari program ini yaitu, yang pertama dapat membeli kebutuhan barang elektronik atau furniture dengan segera. Kedua, proses yang mudah dan cepat. Ketiga, margin yang kompetitif. Keempat, dilindungi asuransi jiwa.

Berdasarkan fitur atau karakteristik dari program pembiayaan Multimanfaat BTN iB, yaitu Angsuran fixed, jangka waktu sampai dengan 10 tahun, dan yang terakhir maksimal pembiayaan sampai dengan $100 \%$ dari harga net barang.

\section{Implementasi Marketing Mixed Tabungan Batara IB Bank BTN Syariah KCPS Parepare}

\section{a. Implementasi Product Tabungan Batara IB Bank BTN Syariah KCPS Parepare}

Produk merupakan salah satu variable utama dalam bauran pemasaran yang didefinisikan sebagai sesuatu yang mempunyai nilai dan manfaat bagi target pasar untuk memenuhi baik kebutuhan maupun keinginannya. Produk merupakan hasil karya cipta manusia apakah produk tersebut berupa jasa atau barang. Dalam hal ini, produk tabungan Batara IB.

Produk Tabungan Batara IB BTN Syariah adalah produk yang menggunakan akad Wadi'ah (titipan), Tabungan Batara IB disebut sebagai produk unggulan di Bank BTN Syariah karena tabungan ini dijadikan basic untuk hampir setiap program yang ada dalam cakupan penghimpunan dana. Contohnya, untuk program Haji dan Umroh, ketika ada nasabah yang hendak mengikuti program tersebut maka diwajibkan membuka rekening induk berupa tabungan Batara IB untuk di auto-debet ke rekening tabungan Haji dan Umroh. ${ }^{4}$ Peneliti beranggap bahwa itulah yang menjadi produk keunggulan dari BTN Syariah dengan setoran awal yang rendah sehingga meringankan dan menarik nasabah untuk menabung.

1) Mendapatkan bonus menarik sesuai ketentuan dari bank, Contohnya, bank akan memberikan bonus atas dasar saldo terendah apapun saldo rata-rata harian nasabah, namun bonus ini tidak dijanjikan di awal besarannya seperti tabungan mudharabah.

${ }^{4}$ Haspar, Customer Service, Jalan Andi Makkasau, Kota Parepare, wawancara oleh penulis di Jln. Andi Makkasau, 12 Oktober 2018. 
2) Imbalan dapat dipotong untuk zakat, infaq, dan sedekah. Nasabah dapat mengajukan kepada bank pada saat pembukaan rekening dilakukan terkait presentase pemotongan otomatis ketika nasabah mendapatkan bonus atas tabungannya.

3) Penyetoran dan penarikan dapat dilakukan diseluruh outlet BTN Syariah dan Konvensional yang menjadi kantor Layanan Syariah diseluruh wilayah Indonesia ${ }^{5}$

Produk ini dibuat sesuai kebutuhan masyarakat untuk memudahkan menabung. Adapun yang menjadi pengamatan peneliti pada saat melaksanakan penelitian di Bank Tabungan Negara Kantor Cabang Pembantu Syariah Parepare yang menjadi syarat untuk menggunakan produk Batara iB ialah berikut informasi terkait pembukaan rekening produk Tabungan BTN Syariah Batara $\mathrm{IB}^{6}$ :

Tabel 1 Informasi Pembukaan Rekening

\begin{tabular}{|l|l|}
\hline Tujuan Pembukaan & Untuk keperluan sehari-hari \\
\hline Setoran Awal & Minimal Rp 100.000,- \\
\hline Bonus & Sesuai ketentuan bank \\
\hline Fasilitas & Kartu ATM/Debit BTN Syariah \\
\hline
\end{tabular}

Sumber Data: Customer Service Tahun 2018

Tabungan Batara IB ini dapat digunakan baik untuk perorangan maupun lembaga, persyaratan bagi nasabah yang hendak melakukan pembukaan rekening adalah sebagai berikut ${ }^{7}$ :

Tabel 2 Persyaratan Pembukaan Rekening

\begin{tabular}{|c|c|c|}
\hline \multirow{4}{*}{ Perorangan } & $\begin{array}{c}\text { Karga Negara Indonesia } \\
(>17 \text { tahun })\end{array}$ & $\begin{array}{c}\text { Kartu Tanda Penduduk (KTP) / } \\
\text { Surat Mengemudi (SIM) / } \\
\text { Paspor \& Nomor Pokok Wajib Pajak } \\
\text { NPWP) }\end{array}$ \\
\cline { 2 - 3 } & $\begin{array}{c}\text { Warga Negara Indonesia } \\
(<17 \text { tahun }\end{array}$ & $\begin{array}{c}\text { Kartu pelajar, Akta lahir, dan Surat } \\
\text { pernyataan orang tua }\end{array}$ \\
\cline { 2 - 3 } & Warga Negara Asing & $\begin{array}{c}\text { Paspor \& Kartu izin tinggal terbatas } \\
\text { (KITAS)/ Kartu izin tinggal tetap } \\
\text { (KITAP) }\end{array}$ \\
\hline Lembaga & & KTP Pejabat Berwenang, Akta \\
\hline
\end{tabular}

${ }^{5}$ Brosur Produk Batara IB, Jalan Andi Makkasau, Kota Parepare, 12 Oktober 2018.

6Bosur Produk Batara IB, Jalan Andi Makkasau, Kota Parepare, 12 Oktober 2018.

${ }^{7}$ Brosur Produk Batara IB, Jalan Andi Makkasau, Kota Parepare, 12 Oktober 2018 


\begin{tabular}{|l|l|c|}
\hline \multirow{1}{*}{} & $\begin{array}{c}\text { pendirian perusahaan, NPWP, Surat } \\
\text { izin usaha perdagangan (SIUP), } \\
\text { Tanda daftar perusahaan (TDP), dan } \\
\text { Surat izin usaha lainnya. }\end{array}$ \\
\hline
\end{tabular}

Sumber Data: Customer Service Tahun 2018

Berdasarkan wawancara yang dilakukan, narasumber mengatakan :

"Sebelum mengeluarkan sebuah produk, maka yang harus diperhatikan adalah bagaimana sasaran pasarnya terkait produk tersebut. Kita harus menguasai produk tersebut serta tujuan yang ingin dicapai untuk mendapatkan keuntungan. Kami melihat produk tabungan Batara IB ini cocok untuk diterapkan karena akan memudahkan keseharian nasabah untuk menabung". 8

\section{b. Implementasi Price Tabungan Batara IB Bank BTN Syariah KCPS Parepare}

Berdasarkan hasil wawancara dari Pak Haspar bahwa Program penetapan margin di Bank BTN Syariah ialah ditentukan oleh pusat yang. Dalam menetapkan harga yang dapat dinilai kompetitif dengan bonus yang akan didapat sesuai dengan kebijakan bank. Nasabah pun memilih jika ingin menyalurkan bonusnya secara langsung untuk keperluan zakat, infaq, dan sedekah kepada lembaga yang sudah bekerja sama dengan Bank BTN Syariah. ${ }^{9}$

Pada produk Tabungan BTN Syariah Batara IB harga yang ditetapkan adalah sebagai berikut ${ }^{10}$

Tabel 3 DISTRIBUSI PENDAPATAN BAGI HASIL DANA PIHAK KE 3

Reff PBI Nomor 7/6/PBI/2005

Bulan SEPTEMBER 2018

${ }^{8}$ Haspar, Customer Service, Jalan Andi Makkasau, Kota Parepare, wawancara oleh penulis di Jln. Andi Makkasau, 12 Oktober 2018.

${ }^{9}$ Haspar, Customer Service, Jalan Andi Makkasau, Kota Parepare, wawancara oleh penulis di Jln. Andi Makkasau, 15 Oktober 2018.

${ }^{10}$ Brosur Tabel Distribusi Pendapatan Bagi Hasil Dana Pihak Ke 3 Reff PBI Nomor 7/6PBI/2005, Jln. Andi Makkasau, 15 Oktober 2018. 


\begin{tabular}{|c|c|c|c|c|c|c|}
\hline & DANA & RATA & & & & \begin{tabular}{|c} 
BONUS \\
DAN BAGI \\
HASIL
\end{tabular} \\
\hline $\mathrm{I}$ & GIRO BTN iB & $\begin{array}{l}2,328,929,002,66 \\
9\end{array}$ & $19.45 \%$ & $\begin{array}{l}22,650,350,14 \\
6\end{array}$ & & $485,193,542$ \\
\hline II & $\begin{array}{l}\text { GIRO BTN } \\
\text { PRIMA iB } \\
\text { GIRO BTN } \\
\text { PRIMA iB } \\
\text { GIRO BTN } \\
\text { PRIMA iB } \\
\text { GIRO BTN } \\
\text { PRIMA iB } \\
\text { GIRO BTN } \\
\text { PRIMA IB } \\
\text { GIRO BTN } \\
\text { PRIMA iB }\end{array}$ & $\begin{array}{l}47,382,839,981 \\
36,892,566,657 \\
31,060,728,788 \\
53,078,596,578 \\
946,151,239,918 \\
2,054,327,913\end{array}$ & $\begin{array}{l}0.40 \% \\
0.31 \% \\
0.26 \% \\
0.44 \% \\
7.90 \% \\
0.02 \%\end{array}$ & $\begin{array}{l}460,828,955 \\
368,804,221 \\
302,085,802 \\
516,223,894 \\
9,201,936,535 \\
19,979,676\end{array}$ & $\begin{array}{c}7.00 \% \\
9.67 \% \\
11.61 \% \\
11.71 \% \\
14.00 \% \\
7.25 \%\end{array}$ & $\begin{array}{l}32,258,027 \\
34,696,368 \\
35,072,162 \\
60,449,818 \\
1,288,271,1 \\
15 \\
1,448,527\end{array}$ \\
\hline III & $\begin{array}{l}\text { TAB. BTN } \\
\text { BATARA iB } \\
\text { TAB. BTN } \\
\text { BATARA iB- } \\
\text { PELAJAR } \\
\text { TAB.BATARA } \\
\text { WADIAH } \\
\text { TERENCANA } \\
\text { TABUNGANKU } \\
\text { iB } \\
\text { TABUNGAN } \\
\text { PAYROLL Ib } \\
\text { TABUNGAN } \\
\text { BTN BATARA iB- } \\
\text { TKI } \\
\text { TABUNGAN } \\
\text { SIMPEL iB } \\
\text { TABUNGAN } \\
\text { BTN PRIMA iB } \\
\text { TABUNGAN } \\
\text { BTN PRIMA iB } \\
\text { TABUNGAN } \\
\text { BTN PRIMA iB } \\
\text { TABUNGAN } \\
\text { BTN PRIMA iB } \\
\text { TABUNGAN } \\
\text { BTN PRIMA iB } \\
\text { TABUNGAN } \\
\text { BTN HAJI \& } \\
\text { UMROH iB } \\
\text { PROG TAB BTN } \\
\text { HAJI \& UMROH } \\
\text { iB } \\
\text { TABUNGAN } \\
\text { QURBAN BTN } \\
\text { iB } \\
\text { TERENCANA }\end{array}$ & $\begin{array}{l}604,113,200,480 \\
25,804,419,372 \\
1.140,803,989 \\
5,324,662,788 \\
15,229,346,377 \\
12,537,369 \\
2,037,545,211 \\
1,164,405,030,51 \\
8 \\
18,797,217,997 \\
42,471,037,018 \\
55,683,102,904 \\
784,813,974,419 \\
85,983,011,213 \\
1,564,160,039 \\
1,698,510,363 \\
37,827,852,741 \\
456,992,789 \\
70,023,333\end{array}$ & $\begin{array}{l}5.04 \% \\
0.22 \% \\
0.01 \% \\
0.04 \% \\
0.13 \% \\
0.00 \% \\
0.02 \% \\
9.72 \% \\
0.16 \% \\
0.35 \% \\
0.46 \% \\
6.55 \% \\
0.72 \% \\
0.01 \% \\
\\
0.01 \% \\
0.32 \% \\
0.00 \% \\
0.00 \%\end{array}$ & $\begin{array}{l}5,875,394,013 \\
250,964,772 \\
11,095,062 \\
51,785,811 \\
148,115,305 \\
121,935 \\
19,816,454 \\
11,324,596,68 \\
0 \\
182,815,177 \\
413,058,473 \\
541,554,412 \\
7,632,826,633 \\
836,240,741 \\
15,212,475 \\
16,519,118 \\
367,900,485 \\
4,444,552 \\
681,022\end{array}$ & $\begin{array}{l}25.00 \% \\
40.00 \% \\
42.00 \% \\
43.00 \% \\
44.00 \% \\
15.50 \% \\
5.00 \% \\
15.50 \% \\
5.25 \% \\
25.00 \% \\
2.00 \%\end{array}$ & $\begin{array}{l}125,856,917 \\
5,375,921 \\
237,667 \\
1,109,305 \\
3,172,780 \\
2,612 \\
424,489 \\
2,831,149,1 \\
773,126,071 \\
73,126,071 \\
173,484,559 \\
232,869,397 \\
3,358,443,7 \\
19 \\
129,617,315 \\
760,624 \\
2,560,463 \\
19,314,775 \\
1,111,138 \\
13,620\end{array}$ \\
\hline
\end{tabular}




\begin{tabular}{|c|c|c|c|c|c|c|c|}
\hline & $\begin{array}{l}\text { TABUNGAN } \\
\text { BTN EMAS iB } \\
\text { TABUNGAN } \\
\text { BTN PRIMA HL }\end{array}$ & & & & & & \\
\hline IV & $\begin{array}{l}\text { DEPOSITO } \\
\text { BATARA } \\
\text { SYARIAH iB } \\
1 \text { BULAN } \\
3 \text { BULAN } \\
6 \text { BULAN } \\
12 \text { BULAN } \\
24 \text { BULAN } \\
\text { DEPOSITO ON } \\
\text { CALL }\end{array}$ & $\begin{array}{l}3,790,907,617,60 \\
6 \\
1,760,076,177,57 \\
5 \\
89,275,409,564 \\
14,937,588,974 \\
7,599,999 \\
27,378,999,996\end{array}$ & $\begin{array}{l}31,66 \% \\
14,70 \% \\
0.75 \% \\
0.12 \% \\
0.00 \% \\
0.23 \%\end{array}$ & $\begin{array}{l}36,869,043,58 \\
4 \\
17,117,886,22 \\
7 \\
868,261,455 \\
145,277,773 \\
73,914 \\
266,278,590\end{array}$ & $\begin{array}{l}40.00 \% \\
43.00 \% \\
44.00 \% \\
44.00 \% \\
39.00 \% 2 \\
5.00 \%\end{array}$ & $\begin{array}{l}14,747,617, \\
434 \\
7,360,691,0 \\
78 \\
382,035,040 \\
63,922,220 \\
28,826 \\
66,569,648\end{array}$ & $\begin{array}{l}4.67 \\
\% \\
5.02 \\
\% \\
5.14 \\
\% \\
5.14 \\
\% \\
4.55 \\
\% \\
2.92 \\
\%\end{array}$ \\
\hline & TOTAL & $\begin{array}{l}11,975,566,125,2 \\
38\end{array}$ & $\begin{array}{l}100.00 \\
\%\end{array}$ & $\begin{array}{l}116,470,173,8 \\
92\end{array}$ & & $\begin{array}{l}31,516,883, \\
345\end{array}$ & \\
\hline
\end{tabular}

Sumber Data: Customer Service Tahun 2018

Peneliti mengungkapkan bahwa setiap produk yang ada di dalam perbankan mempunyai karakteristik dan ketentuan masing-masing, begitupun dengan harga yang dibebankan.

\section{c. Implementasi Place Tabungan Batara IB Bank BTN Syariah KCPS Parepare}

Place/lokasi, Berdasarkan pemikiran peneliti bahwa lokasi/tempat yang strategis sebelum menentukan sebuah lokasi terlebih dahulu menyesuaikan jenis produk yang ditawarkan. Program Produk Batara iB dipasarkan ke semua masyarakat maupun kalangan menengah kebawah dan memilih pusat keramaian pasar, dalam produk ini tidak menanjikan bagi hasil kepada nasabah melainkan memberikan bonus yang menguntungkan. Peneliti beranggap bahwa produk tabungan Batara IB yamg dilaksanakan oleh Bank BTN Syariah KCPS Parepare dalam memasarkan produk terkhusus tabungan Batara iB disemua kalangan masyarakat karena produk ini hanya dihadirkan sebagai media penyimpanan dana, dan tidak menjanjikan bagi hasil.

Lokasi dalam perbankan dapat diartikan sebagai tempat dimana terjadinya jual beli terhadap produk-produk bank. Memilih atau menentukan lokasi tempat usaha yang strategis akan mempengaruhi kesuksesan bisnis yang dijalankan. Selain itu, kondisi yang tepat juga akan berperan penting pada produk yang ditawarkan. Memang tidak mudah dalam mendapatkan lokasi tempat usaha pada spot yang strategis, apalagi harus meraut modal yang besar. Sebelum menentukan lokasi yang dipilih, juga harus menyesuaikan jenis usaha yang dijalankan. 
Berdasarkan observasi lapangan yang dilakukan oleh peneliti, peneliti mendeskripsikan hasil penelitian terkait strategi memilih tempat (place) yang baik, yakni sebagai berikut :

1) Tempat Beribadah (Masjid)

Setiap individu tenaga marketing mempunyai teknik yang berbeda dengan pemasar yang lain, mereka diharuskan memiliki inovasi sendiri untuk bertarung dengan pemasar yang lain. Masjid/Mushallah merupakan tempat ibadah umat islam yang utama, pada zaman Rasulullah Masjid juga dimanfaatkan sebagai pusat perekonomian. Kalau kita berbicara mengenai produk Bank Syariah, nasabah yang menjadi target awal adalah para calon nasabah yang memiliki kedekatan pengetahuan terhadap Islam. Segmen ini bisa kita dapatkan pada jam-jam sholat seperti sholat Zuhur dan Ashar. Seperti Masjid di pusat Kota jama'ahnya selalu di dominasi oleh para pengusaha-pengusaha dan pegawai. ${ }^{11}$

Peneliti beranggap bahwa, ini salah satu pemikiran baik pada bagian marketing, disinilah peluang pemasaran yang bisa dijalankan setelah selesai sholat biasanya jama'ah bersantai sejenak. Bank BTN Syariah KCPS Parepare memilih lokasi untuk memasarkan produk Tabungan Batara IB di Masjid, di hari kedua meneliti, peneliti ikut serta menawarkan program-program produk yakni, Tabungan Batara IB, Tabungan Prima IB, Tabungan Bernisbah lebih (Tasbih) BTN IB, dan terkhusus untuk Tabungan Haji dan Umroh.

Berdasarkan beberapa kondisi diatas, peneliti simpulkan bahwa, sudah saatnya pemasaran produk bank syariah di arahkan kepada segmen pasar yang tepat yaitu kepada calon nasabah yang sering melakukan aktifitasnya di Masjid/Mushallah.

2) Memilih Pusat Keramaian Pasar

Lokasi Bank BTN Syariah KCPS Parepare yakni terletak di pusat Kota Parepare tepatnya di Jalan Andi Makkasau, yang mana lokasi tersebut adalah pusat perhotelan dan perkantoran, yang menandakan ekonomi masyarakat Kota Parepare adalah baik.

Bank BTN Syariah KCPS Parepare diapit oleh dua hotel, dan berada di tengah kota, dan di tengah-tengah para pesaing Lembaga Pembiayaan lainnya seperti Perbankan Konvensional dan Pengkreditan Lainnya disekitar lokasi tersebut. Peneliti beranggapan bahwa ini menunjukkan daya saing yang cukup kuat dilokasi tersebut untuk perebutan pangsa pasar.

3) Memasuki Pusat Target Pasar

Parepare menjadi pusat pasar yang sekarang dilirik oleh para stakeholder, sebab perekonomian masyarakat Kota Parepare kian meningkat sedang harga kebutuhan pokok masih relatif murah dan terjangkau dibandingkan dengan daerah Ajattappareng lainnya. Dari ke-5 Kabupaten yang tergabung di dalam wilayah Ajattappareng ( Parepare, Barru,

${ }^{11}$ Haspar, Customer Service, Jalan Andi Makkasau, Kota Parepare, wawancara oleh penulis di Jln. Andi Makkasau, 18 Oktober 2018. 
Pinrang, Sidrap dan Enrekang ) Kota Parepare-lah yang menduduki posisi wilayah yang paling baik untuk menggarap bisnis, sebab perputaran perekonomiannya cepat. ${ }^{12}$

Peneliti menyumpulkan bahwa, Inilah alasan utama Bank BTN Syariah memilih Kota Parepare sebagai tempat mendirikan kantor untuk beroperasi di Sulawesi Selatan selain di Kota Makassar, sebab Bank BTN Syariah datang ditengah-tengah pangsa pasar untuk merangkul para develover dan nasabah untuk memfasilitasi mereka akan pengadaan perumahan.

\section{d. Implementasi Promotion (Promosi) Tabungan Batara IB Bank BTN Syariah KCPS Parepare}

Promosi merupakan langkah yang sangat penting, tanpa promosi jangan harapkan nasabah dapat mengenal Bank. Oleh karena itu, Program promosi merupakan sarana yang paling ampuh untuk menarik dan mempertahankan nasabahnya. Salah satu tujuan promosi Bank adalah menginformasikan segala jenis produk yang ditawarkan dan berusaha menarik calon nasabah yang baru.

Dari hasil wawancara kepada narasumber, peneliti diberikan brosur sarana dalam mempromosikan baik produk maupun jasanya. Beberapa macam yang digunakan oleh Bank BTN Syariah adalah :

1) Periklanan (advertising);

2) Promosi penjualan (sales promotion);

3) Publisitas (publicity);

4) Penjualan pribadi (personal selling). ${ }^{13}$

Penggunaan promosi dapat dilakukan dengan berbagai media seperti;

1) Pemasangan billboard di jalan-jalan strategis;

2) 2.Pencetakan brosur baik disebarkan di setiap cabang atau pusat-pusat perbelanjaan;

3) Pemasangan spanduk di lokasi tertentu;

4) Pemasangan melalui koran;

5) Pemasangan melalui majalah;

6) Pemasangan melalui televisi;

7) Pemasangan melalui radio dan menggunakan media lainnya.

Berdasarkan pertimbangan penggunaan media yang akan dipakai untuk pemasangan iklan di suatu media antara lain:

\footnotetext{
${ }^{12}$ Asriadi Arifin," Strategi Bank BTN Syariah KCPS Parepare dalam Memasarkan Produk (Analisis Manajemen syariah)". Jurusan Perbankan Syariah Fakultas Syariah dan Ekonomi Islam IAIN Parepare, 2017.

${ }^{13}$ Haspar, Customer Service, Jalan Andi Makkasau, Kota Parepare, wawancara oleh penulis di Jln. Andi Makkasau, 18 Oktober 2018.
} 
1) Jangkauan media yang akan digunakan;

2) Sasaran atau konsumen yang akan dituju;

3) Tujuan iklan tersebut;

4) Biaya yang akan dikeluarkan ${ }^{14}$

Maka peneliti beranggapan, dibutuhkan promosi yang menarik agar nasabah merasa penasaran dengan produk tersebut, yang harus dilakukan oleh seorang pemasar Bank Syariah yaitu, Meyakinkan pelanggan akan produk yang tidak nyata melalui presentase produk yang menarik dan proses penjualan efektif yang tergantung pada ketajaman dan kejelian dalam melakukan pendekatan penjualan.

Pendekatan-pendekatan demikianlah yang harus dilakukan dalam mempromosikan produk untuk menarik nasabah sebanyak-banyaknya. Pemasar pada Bank Syariah harus memiliki kualifikasi pembacaan nasabah yang baik untuk melakukan penjualan. Melalui observasi lapangan yang telah dilakukan, penulis mendeskripsikan promosi yang diterapkan oleh Bank BTN Syariah KCPS Parepare, yakni :

1) Promosi

2) Sosial Media

3) Brosur, dan

4) Periklanan

Promosi BTN Syariah Goes To Campus pernah dilakukan oleh Pimpinan Bank BTN Syariah KCPS Parepare, yakni Bapak Sulthon Agung Pimpinan pertama pada saat berdirinya Bank BTN Syariah KCPS Parepare yang pada waktu itu penulis melakukan Program Pengalaman Lapangan (PPL) di Bank tersebut. Bapak Sulthon Agung menghadiri seminar Job Seeker Training yang diadakan oleh kampus IAIN Parepare pada Oktober 2017 lalu. Sambil memberikan pelatihan mencari kerja kepada mahasiswa Perbankan Syariah, Ia juga memperkenalkan Bank BTN Syariah kepada Mahasiswa berikut kiat-kiat untuk melamar kerja pada Bank tersebut pun ia sarankan. Penulis mengamati promosi yang demikian cukup efisien sebab tidak memakan biaya sama sekali (gratis). ${ }^{15}$

\section{e. Implementasi People Tabungan Batara IB Bank BTN Syariah KCPS Parepare}

Sumber daya manusia (SDM) salah satu faktor yang sangat penting di dalam suatu organisasi dalam halnya lembaga Perbankan yang termasuk di dalam lingkungan suatu organisasi, Baik dari investor, pimpinan, pengelola, hingga para pekerja lapisan bawah sampai kepada tenaga keamanan Bank tersebut.

${ }^{14}$ Kasmir,"Manajemen Perbankan Edisi Revisi"(Jakarta:PT RajaGrafindo Persada,2000) h. 246

${ }^{15}$ Asriadi Arifin," Strategi Bank BTN Syariah KCPS Parepare dalam Memasarkan Produk (Analisis Manajemen syariah)". Jurusan Perbankan Syariah Fakultas Syariah dan Ekonomi Islam IAIN Parepare, 2017. 
People meliputi kegiatan untuk karyawan seperti kegiatan recruitment, pendidikan dan training, motivasi, balas jasa, dan kerja sama serta pelanggan yang menjadi nasabah atau calon nasabah. ${ }^{16}$

Berdasarkan dari observasi peneliti program yang dilaksanakan di Bank BTN Syariah KCPS Parepare :

1) Kegiatan Briefing

Secara umum briefing dilakukan oleh semua lembaga perbankan, baik Bank Konvensional maupun Bank Syariah. Ini sudah menjadi ketetapan budaya kerja setiap hari kerja. Berdasarkan dari penulis tersebut yang pernah terjun langsung melakukan Program Pengalaman Lapangan (PPL) di Bank BTN Syariah KCPS Parepare bahwa, Waktu saya praktek di Bank BTN Syariah, Jam 7:30 itu sudah mulai breafing biasanya sampai jam 08:00. Di dalam breafing di awali dengan do'a bersama untuk kesejahteraan Bank, nasabah dan para karyawan. Setelah itu, dipersilahkan pimpinan cabang pembantu untuk memaparkan masalah kantornya dan menyampaikan produk baru yang dikeluarkan oleh Bank BTN Syariah, yakni, Tabungan Haji.

2) Perekrutan Karyawan

Dari observasi lapangan yang dilakukan, peneliti melihat jumlah karyawan Bank BTN Syariah KCPS Parepare adalah sebanyak 7 orang karyawan, termasuk didalamnya adalah pimpinan, Account Officer (AO), suvervisor, customer service/Funding, teller dan security.

Berdasarkan wawancara dari Pak Haspar bahwa, penerimaan karyawan baru yang di khususkan untuk unit funding officer. Unit ini adalah unit yang masih memandang bahwa marketing terkhusus di ranah funding adalah unit yang pekerjaannya sulit dan selalu penuh tekanan akan target. Namun menurut Pak Aspar yang sudah berada di unit tersebut tidak merasakan apa yang menjadi kekhawatiran calon karyawan. Walaupun memang benar unit selalu diberikan target, namun target tersebut bukanlah suatu hal yang perlu ditakuti. ${ }^{17}$

3) Tenaga Keamanan Kantor (security)

Pengamanan dalam sebuah lembaga sangat penting. Tingkat keamanan yang minim akan memudahkan oknum tertentu untuk mengganggu kelangsungan operasionalisasi lembaga. Misalnya, tindakan tindakan pencurian atau perampokan sehingga perlu keamanan yang memadai. Bank BTN Syariah KCPS Parepare menempatkan dua tenaga keamanan (security) yang piket.

${ }^{16}$ Kasmir, Pemasaran Bank, edisi revisi dan diperluas (Cet. III; Jakarta: Kencana, 2008), h. 120.

${ }^{17} \mathrm{Haspar}$, Customer Service, Jalan Andi Makkasau, Kota Parepare, wawancara oleh penulis di Jln. Andi Makkasau, 23 Oktober 2018. 
Berdasarkan dari wawancara kepada Pak Renaldi dan Pak Hendra selaku keamanan, Bank BTN Syariah KCPS Parepare itu sendiri menerapkan sistem penjagaan sekali 12 jam untuk seorang security masuk jam 7.00 dan lepas jaga jam 19.00, kemudian akan digantikan oleh kemanan jaga malam sampai jam 7.00.

\section{f. Implementasi Physical Evidance Tabungan Batara IB Bank BTN Syariah KCPS Parepare}

Physical Evidence atau bukti fisik terdiri dari adanya logo atau simbol perusahaan, moto, fasilitas yang dimiliki, seragam karyawan, laporan, kartu nama, dan jaminan perusahaan. ${ }^{18}$ Program Bukti fisik adalah semua fasilitas yang berbentuk fisik yang dapat dirasakan oleh nasaba, Berikut hasil observasi penelitian :

1) Lingkungan Eksterior

Lingkungan luar (eksterior) pada Bank BTN Syariah KCPS Parepare terlihat bersih dan rapi tempat parkiran nasabah, Namun peneliti menilai area parkir kendaraan sempit untuk kuantitas nasabah yang banyak, sehingga kendaraan nasabah biasa sampai di pinggir jalan raya. Tampak depan penataan design kantornya kelihatan mewah dengan warna kuning dan biru sebagaimana ciri khas Bank BTN bentuknya memanjang keatas sampai lantai 3, di depan kantor terpasang billboard reklame sebagai penanda kantor yang kelihatan menyala di malam hari.

2) Lingkungan Interior

Tata ruang bagian dalam kantor (interior) pada Bank BTN Syariah KCPS Parepare secara umum nyaman dan bersih. Di area banking hall depan meja kerja Customer Service dan Teller di letakkan kursi memanjang tempat memunggu antrian, di seluruh ruang kerja dilengkapi pendingin AC dan pengharum ruangan sehingga membuat nasabah yang datang merasa nyaman.

Di lantai 2 terdapat ruangan pimpinan, ruangan karyawan, dan ruangan rapat, dan di lantai 3 sebuah Mushollah yang cukup nyaman untuk melakukan ibadah bagi karyawan kantor ataupun nasabah. Peneliti sangat setuju adanya Mushollah dan semoga dapat menjadi contoh dari lembaga-lembaga keuangan lainnya. terlebih lagi ini adalah Lembaga Perbankan Syariah.

3) Automatic Teller Mechine (ATM)

Peneliti melihat fasilitas ATM berada di pintu depan sebelah kiri ketika nasabah masuk ke dalam Bank BTN Syariah KCPS Parepare, peneliti menilai penempatannya cukup baik dan aman, sebab tetap ada security yang tiap hari piket. Namum, kekurangannya adalah masih jarang ditemukan ATM khusus BTN Syariah di Kota Parepare sehingga ketika

18Kasmir,'Manajemen Perbankan Edisi Revisi”'(Jakarta:PT RajaGrafindo Persada,2000) h. 214 
nasabah ingin melakukan penarikan tunai harus langsung datang ke bank, yang jadi masalah apabila nasabahnya jauh.

4) Mesin Penghitung Uang Tunai

Mesin penghitung uang adalah sebuah alat bantu untuk kasir atau teller dalam menghitung jumlah uang yang ditransaksikan. Mesin ini dengan mudah mampu menghitung jumlah uang yang banyak hanya se-efesien mungkin.

Berdasarkan hasil observasi peneliti di Kantor BTN Syariah KCPS Parepare bahwa, kekurangan dilingkungan Eksterior ialah area parkiran kendaraan nasabah yang kurang memadai sehingga kendaraan nasabah diparkir sampai di pinggir jalan raya maka terlihat tidak rapi.

\section{g. Implementasi Process Tabungan Batara IB Bank BTN Syariah KCPS Parepare}

Proses pembiayaan Batara IB pada Bank BTN Syariah KCPS Parepare menggunakan akad Wadiah. Bank BTN Syariah KCPS Parepare menggunakan program dengan akad Wadia'ah adalah titipan nasabah yang harus dijaga dan dikembalikan setiap saat nasabah yang bersangkutan menghendaki. Bank bertanggungjawab atas pengembalian titipan tersebut. Secara sederhana mengenali pasar adalah melihat, mengikuti perkembangan pasar, membandingkan dengan produk sendiri. ${ }^{19}$

1) Dasar hukum akad Wadi'ah

QS.An-Nissa' : 58

Artinya : Sesungguhnya Allah menyuruh kamu menyampaikan amanat kepada yang berhak menerimanya, dan (menyuruh kamu) apabila menetapkan hukum di antara manusia supaya kamu menetapkan dengan adil. Sesungguhnya Allah memberi pengajaran yang sebaik-baiknya kepadamu. Sesungguhnya Allah adalah Maha mendengar lagi Maha Melihat. ${ }^{20}$

2) Prosedur Pembukaan Buku Tabungan

Berikut program prosedur pembukaan buku tabungan yang didapatkan oleh peneliti :

${ }^{19}$ Haspar, Customer Service, Jalan Andi Makkasau, Kota Parepare, wawancara oleh penulis di Jln. Andi Makkasau, 1 November 2018.

${ }^{20}$ Q.S. An-Nissa' [4]: 58 

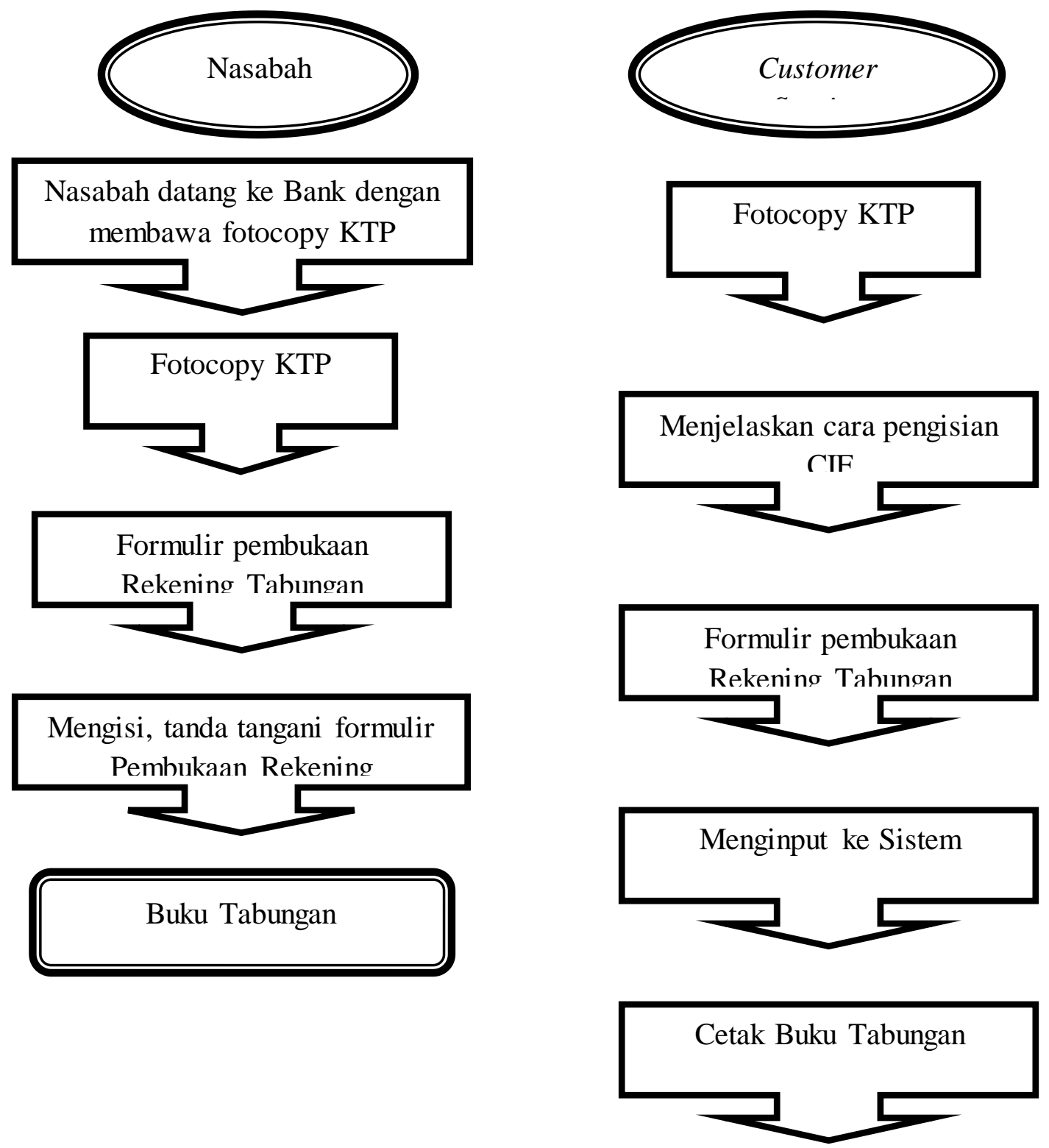

Buku Tabungan

Gambar 1 Prosedur Pembukaan Buku Tabungan

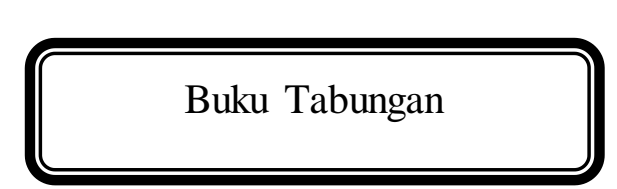

i. Pelaksanaan Tabungan Batara IB dalam Marketing Mix di Bank BTN Syariah KCPS Parepare

a. Pelaksanaan Product Tabungan Batara IB Bank BTN Syariah KCPS Parepare

Berdasarkan hasil wawancara dengan Pak Haspar salah satu pegawai di Bank BTN Syariah KCPS Parepare menjelaskan bahwa produk tabungan Batara IB ini sudah tersusun secara terencana. Yakni produk tabungan Batara IB ini ditekankan kepada masyarakat yang 
ingin menabung dengan cara mudah. Akan tetapi jika ada segmen dan target lain yang masuk di area yang berbeda, asalkan memenuhi syarat jadi diterima saja. ${ }^{21}$

Peneliti beranggapan bahwa Bank BTN Syariah KCPS Parepare tidak membeda-bedakan tidak pandang bulu siapa saja yang ingin melakukan simpanan atau tabungan. Sementara itu Bank BTN Syariah KCPS Parepare sudah mempunyai segmen pasar dan target yang menjadi prioritas.

\section{b. Pelaksanaan Price Tabungan Batara IB Bank BTN Syariah KCPS Parepare}

Berdasarkan wawancara dari Pak Haspar bahwa pelaksanaan harga pembukaan buku rekening tabungan Batara IB ialah setoran awal sebesar Rp 100.000 dan mengendap Rp 100.000 Untuk tabungan Batara IB ini menggunakan akad wadi'ah (titipan), jadi nasabah tidak mendapatkan bagi hasil, melainkan mendapatkan bonus dari bank, namun tidak diperjanjikan. Dengan harga yang terjangkau, semua nasabah baik yang nasabah KPR maupun non KPR dapat memilki rekening tabungan tersebut. ${ }^{22}$

Peneliti beranggapan bahwa produk tabungan Batara IB yang ada di Bank BTN Syariah ini diperuntukkan bagi masyarkat luas.

\section{c. Pelaksanaan Place Tabungan Batara IB Bank BTN Syariah KCPS Parepare}

Berdasarkan hasil wawancara dari Pak Haspar bahwa, letak fisik yang meliputi bangunan yang berhubungan dengan tempat akan mempengaruhi seorang nasabah untuk menggunakan jasa di bank. Lokasi Bank BTN Syariah KCPS Parepare yang strategis di tengah keramain kota dan pesain lembaga-lembaga keuangan lainnya, menjadikan kenyamanan untuk merangkul sebanyak-banyaknya devlover. dan menjadikan Bank BTN Syariah KCPS tersebut memperlihatkan kemampuan yang ekstra memperlihatkan daya saing yang kuat dan berbeda. ${ }^{23}$

Peneliti beranggapan bahwa Memilih atau menentukan lokasi tempat usaha yang strategis akan mempengaruhi kesuksesan bisnis yang dijalankan. Maka peneliti simpulkan bahwa lokasi Bank BTN Syariah KCPS Parepare sangat baik karena berada di tengah kota dekat dari pusat perbelanjaan.

\section{d. Pelaksanaan Promotion Tabungan Batara IB Bank BTN Syariah KCPS Parepare}

Berdasarkan hasil wawancara dari Pak Haspar bahwa, Promosi merupakan cara berkomunikasi yang dilakukan oleh perusahaan untuk mendorong atau menarik calon konsumen atau nasabah agar membeli produk atau jasa yang dipasarkan. Ada empat alat utama untuk promosikan produk tersebut, yakni : iklan, promosi penjualan, publisitas, dan penjualan pribadi. ${ }^{24}$

\footnotetext{
${ }^{21}$ Haspar, Customer Service, Jalan Andi Makkasau, Kota Parepare, Brosur, 2 November 2018

${ }^{22}$ Haspar, Customer Service, Jalan Andi Makkasau, Kota Parepare, Brosur, 2 November 2018

${ }^{23}$ Haspar, Customer Service, Jalan Andi Makkasau, Kota Parepare, Brosur, 5 November 2018

${ }^{24}$ Haspar, Customer Service, Jalan Andi Makkasau, Kota Parepare, Brosur, 5 November 2018
} 
Peneliti menyimpulkan bahwa ke empat alat promosi tersebut bentuk promosi dari mulut kemulut sehingga tidak memerlukan banyak biaya dalam promosi tersebut.

\section{e. Pelaksanaan People Tabungan Batara IB Bank BTN Syariah KCPS Parepare}

Berdasarkan hasil wawancara dari Pak Haspar bahwa, dalam suatu perusahaan dipilih dengan melalui adanya perekrutan karyawan. Seleksi, training dan pelatihan. Serta dengan motivasi karyawan sehingga bisa bekerjasama team. Berhubungan dengan pemasaran jasa sangat mempengaruhi kualitas jasa yang diberikan. Prospek yang harus dilakukan supaya karyawan memperhatikan kompetensi, sikap, inisiatif dan respon. ${ }^{25}$

Peneliti beranggapan bahwa karyawan Bank BTN Syariah KCPS Parepare harus mampu memecahkan masalah, serta etika dan niat yang baik sehingga pekerjaan akan berjalan dengan lancar dan kompak sehingga mereka lebih semangat dalam mencapai target kinerja yang sudah direncanakan.

\section{f. Pelaksanaan Physical Evidence Tabungan Batara IB Bank BTN Syariah KCPS Parepare}

Berdasarkan wawancara dari Pak Haspar menyatakan bahwa bukti fisik merupakan lingkungan perusahaan dalam bentuk lingkungan eksterior tampak depan penataan design kantor kelihatan mewah dengan warna kuning dan biru dan terdapat ATM disisi kiri, kemudian depan kantor terpasang billboard reklame. Lingkungan interior terdapat tempat duduk antrian nasabah dan dilengkapi AC, pengharum ruangan dan terdapat mesin penghitung uang tunai alat bantu teller untuk menghitung jumlah uang. Adapun mushollah yang kami siapkan cukup nyaman bagi nasabah atau karyawan untuk melakukan ibadah. ${ }^{26}$

Peneliti beranggapan bahwa secara keseluruhan Bank BTN Syariah KCPS Parepare telah menyiapkan tempat yang nyaman sehingga nasabah tidak merasa bosan apabila menunggu antrian dengan kelengkapan TV dan aroma yang sangat bagus.

\section{g. Pelaksanaan Process Tabungan Batara IB Bank BTN Syariah KCPS Parepare}

Berdasarkan wawancara dari Pak Haspar bahwa, proses merupakan gabungan semua aktivitas umumnya yang terdiri dari prosedur, pekerjaan yang rutin. Dan proses ini sangat penting karena keharusan yang wajib untuk dijalankan. Salah satunya jadwal kerja yang sudah menjadi aturan. ${ }^{27}$

Peneliti menyimpulkan bahwa, dimana proses merupakan elemen yang sangat penting bagi perusahaan dan yang dapat memperhatikan secara tidak langsung kualitas jasa yang diberikan kepada nasabah.

25Haspar, Customer Service, Jalan Andi Makkasau, Kota Parepare, Brosur, 7 November 2018

${ }^{26}$ Haspar, Customer Service, Jalan Andi Makkasau, Kota Parepare, Brosur, 7 November 2018

${ }^{27}$ Haspar, Customer Service, Jalan Andi Makkasau, Kota Parepare, Brosur, 8 November 2018 


\section{Kesimpulan}

Berdasarkan hasil penelitian dan pembahasan maka penulis uraikan diatas mengenai Implementasi Marketing Mix pada Tabungan Batara IB Bank BTN Syariah KCPS Parepare dapat disimpulkan bahwa :

1. Implementasi Program Tabungan Batara IB dalam Marketing Mix di Bank BTN Syariah KCPS Parepare pada semua elemen yakni product, price, place, promotion, people, physical evidence, process yang sudah terterapkan dengan cukup baik yang saling menyangkutpautkan dengan marketing mix satu dan lainnya.

2. Berdasarkan Pelaksanaan Tabungan Batara IB dalam Marketing Mix di Bank BTN Syariah KCPS Parepare mengimplementasikan pemasaran Tabungan Batara IB yang sudah diterapkan dengan tujuh komponen yang meliputi product, price, place, promotion, people, physical evidence, process merupakan suatu strategi pemasaran yang trans paransi sehingga menciptakan suatu pelaksanaan yang baik. 


\section{Daftar Pustaka}

\section{Buku}

Abd. Somad dan Trisadini P. Usanti Abd. Somad. 2013. Transaksi Bank Syariah. Jakarta: PT Bumi Aksara.

Akbar, Faisal. 2010. Strategi Pemasaran BMT Al Ikhlas Yogyakarta. Skripsi Ekonomi Islam, Yogyakarta, Perpustakaan UII.

Assauri, Sofyan. 2007. Manajemen Pemasaran, Jakarta: PT. Raja Grafindo Persada.

Dirgantoro, Crown.2001. Manajemen Stratejik. Jakarta: PT Grasindo.

Departemen Agama RI. 2009. Al-Quran dan Terjemahan. Jakarta : Pt Mizan Pustaka

Departemen Pendidikan Nasional.2012. Kamus Besar Bahasa Indonesia: Pusat Bahasa, Jakarta: Gramedia Pustaka Utama.

.Kamus Besar Bahasa Indonesia Edisi IV, Jakarta: PT Gramedia Pustaka Utama.

Kasmir.2000. Manajemen Perbankan Edisi Revisi. Jakarta: PT Raja Grafindo Persada.

2006. Kewirausahaan. Jakarta: PT Raja Grafindo.

2008. Pemasaran Bank, edisi revisi dan diperluas. Cet. III; Jakarta: Kencana.

Hasan, Ali. 2010. Marketing Bank Syariah. Jakarta: Ghalia Indonesia.

2010. Marketing Bank Syariah. Bogor: Ghalia Indonesia.

Hilman, Imam. 2003. Perbankan Syari'ah Masa Depan. Jakarta:Senayan Abadi Publishing.

Adiwarman, Karim.2004. Bank Islam:Analisis Fiqh dan Keuangan. Jakarta:PT Raja Grafindo Persada.

Kotler, Philip.1997. Prinsip-Prinsip Pemasaran. Jakarta: Erlangga.

.at al.1996. Manajemen Pemasaran Persfektif Asia. yogjakarta, Pearson Education Asia.

Khaerul Umam dan Herry Susanto. Manajemen Pemasaran Bank Syariah.

Kevin Lane Keller dan Philip Kotler.2008. Manajemen Pemasaran, Edisi 13,Jakarta: Erlangga.

Muhammad.2002. Manajemen Bank Syariah. Yogyakarta: Unit Penerbit dan Percetakan AMPYKPN.

Antonio, Muhammad Syafi'i. 2001. Bank Syariah, Dari Teori ke Praktik, penyunting Basri, Dadi M.H. Farida R. Dewi, Cet. 1, Jakarta: Gema Insani.

Republik Indonesia. 1998. Undang-undang RI Nomor 10 Tahun1998 tentang Perbankan.

Sula, Muhammad Syakir dan Hermawan Kartajaya.2006. Syariah Marketing. Bandung: PT. Mizan Pustaka.

Machfoedz, Mas'ud.2004. Kewirausahaan Metode, Manajemen, dan Implementasi. Yogyakarta:BPFE.

Purnomo, Hari.2004. Perncanaan dan Perancangan Fasilitas. Yogyakarta, Graha Ilmu.

Rangkuti, Freddy.2005. Analisis Swot Teknik Membedah Kasus Bisnis. Jakarta: PT Gramedia Pustaka Utama.

Soemitra, Andri.2009. Bank dan Lembaga Kenangan Syariah. Jakarta: Prenada Media Grup, 2009, Cet Ke 1.

Suryana.2001. Kewirausahaan. Jakarta: PT Salemba Emban Patria. 
Swastha, Basu.1999. Azas-Azas Marketing. Yogyakarta: Liberty Offset Yogyakarta.

Sudarsono, Heri.2004. Bank dan Lembaga Kenangan Syariah. Yogyakarta: Ekonisia.

Sumiyanto, Ahmad.2008. BMT Menuju Koperasi Modern. Jakarta: ISES Publising.

T.H.Goh Sunny, et al.2003. Marketing Wise. Jakarta: Bhuana Ilmu popular.

Umar, Husein.2010. Desain Penelitian Manajemen Strategik:Cara Mudah Meneliti Masalah- Masalah Manajemen Strategik Untuk Skripsi, Tesis, Dan Praktik Bisnis, Jakarta: Rajawali Press.

\section{Skripsi :}

Asriadi Arifin. 2018. “Strategi Bank BTN Syariah KCPS Parepare dalam Memasarkan Produk.” Jurusan Syariah dan Ekonomi Islam prodi Perbankan Syariah, 2018", Jurusan Syariah dan Ekonomi Islam prodi Perbankan Syariah Sekolah Tinggi Agama Islam Negeri (STAIN) Parepare.

Isma Wida Iva. 2015. "Analisis Implementasi Syariab Marketing (Studi Kasus di AJB Bumiputera 1912 Kantor Cabang Syariah Semarang”, Fakultas Ekonomi dan Bisnis Islam Universitas Islam Negeri Walisongo Semarang.

Miftahul Azizah Hasanah. 2016. ” Analisis Penerapan Bauran Pemasaran Pada Produk Jasa Tabungan Di Bank Madinah Syariah Yogyakarta ",Fakultas Dakwah dan Komunikasi Universitas Islam Negeri Sunan Kalijaga Yogyakarta.

\section{Website:}

Bank Rakyat Indonesia Syariah, Visi dan Misi, http://www.brisyariah.co.id

https://www.brainly.co.id/tugas/8964448.

Http://www.banksyariah.com.

http://jurnalrakyaat.blogspot.com. 